\title{
Editorial comment and introduction
}

\section{African societies, nation-states, governance, human migration, xenophobia and cultural contestations: Editorial framing}

\author{
M.P. SEBOLA' AND J. TSHEOLA
}

\section{Introduction}

African societies have continued to be afflicted with deleterious challenges and problems, years after gaining independence from colonialism. Post-colonialism, if it was anything real, was supposed to be preoccupied with the pan-Africanism vision of revaluation of African cultures, respect of human rights of all people on the continent, intensified continental cooperation for sustainable development, peace, security and stability. Instead, Africa has continued to be gripped by internal strife, insecurities and power inequities that manifest along the existing geopolitical entities defined through the socio-political boundaries. Notwithstanding the rejection of the latter's bordering of the nation-states as artificial, African states have continued to order and re-territorialise sovereignty in ways that have accentuated colonially-inspired cultural divides, amounting to "new racism" on the continent (Adjai \& Lazaridis, 2013; Jolly \& DiGiusto, 2014). Whereas the spectrum of Africa's problems is long, human migration together with the attendant xenophobia expressed within local societies against African immigrants have become prominent with repeated violent public abuses in South Africa in 2008 and 2015. For this reason, the Journal for Transdisciplinarity Research in Southern Africa has dedicated this special edition to the unfinished discourses on the African societies, nation-states, governance, human migration, xenophobia and cultural contestations.

\section{African societies, nation-states and governance in international geopolitics}

Societies have ordered themselves through fragmentary geopolitical entities bounded by socio-political boundaries that define de jure sovereignty governed by states (Pereira \& Ruysenaar, 2012; Kark, Tulloch, Gordon, Mazor, Bunnefeld \& Levin, 2015; Thondhlana, Shackleton \& Blignaut, 2015). The African society too has been ordered through similar reterritorialisation of sovereignty along cultural and ethnic divides, creating "bordering, ordering and othering" landscapes (Iossifova, 2013; Lunstrum, 2013; Dallimer \& Strange, 2015; Kark et al., 2015). This territorialisation of sovereignty has enabled conceptions and treatment of African immigrants on the continent as "out-groups" and enemies of nationstates (Adjai \& Lazaridis, 2013; Lunstrum, 2013; Jolly \& DiGiusto, 2014; Dallimer \&

1 School of Economics \& Management, University of Limpopo, Private Bag X1106, Sovenga, 0727, South Africa, E-mail: mokoko.sebola@ul.ac.za

2 Faculty of Management \& Law, University of Limpopo, P.O. Box 313, Fauna Park, 0787, South Africa, E-mail: johannes.tsheola@ul.ac.za 
Strange, 2015). The preeminence of the Western economic philosophy in this "bordering, ordering and othering" of international relations governance is apparent in the ironic dominance of the interpretation of African Renaissance through the globalist modernist, rather than Africanist, perspectives (Moilanen \& Arponen, 2011; van Amerom \& Buscher, 2005; Martin, Rutagarama, Cascao, Gray \& Chhotray, 2011; Dallimer \& Strange, 2015). The understanding of sovereignty through state exercise of power over defined territory is universal, notwithstanding the reality of its complexity and inconsistency (Devine, 2014, Duffy, 2014; Lunstrum, 2014; Dallimer \& Strange, 2015; Massé \& Lunstrum, 2015). Reverence of the existing geopolitical entities in international relations and reinforcement of exercise of power through territorialised sovereignty has impaired the potential for organic spatial socialisation of people on either side of the socio-political boundaries (Lunstrum, 2014; Dallimer \& Strange, 2015; Massé \& Lunstrum, 2015). As a result of the enforcement of governance of international relations along the fragmented geopolitical landscapes, human migration has precipitated the establishment of transnational cultures that signaled "otherness" within local societies (Devine, 2014, Duffy, 2014; Lunstrum, 2014; Massé \& Lunstrum, 2015). Territorialisation of sovereignty in international relations coincides with geopolitical landscapes of peace, war, security, insecurity, legality, illegality, order, disorder, poverty, opulence and so on, prompting large scale international migration across the world, which enabled perceptions of collective threat, fear and siege. To overcome the divisions and potential conflicts encouraged by nation-state governance based on sovereignty-territory relations, spatial socialisation is necessary to bring people across geopolitical entities and socio-political boundaries closer together with increased international migration, contact and interactions.

\section{Human migration, xenophobia and cultural contestations}

Human migration has historically epitomised the development landscapes (Brown \& Connell, 2004; Moses \& Letnes, 2004; Balbo \& Marconi, 2006; Jolly \& DiGiusto, 2014); and, recent occurrences of crowds of Africans drifting into Europe notwithstanding the horrific incidents of drowning in the Mediterranean Sea and sheer sufferance of elements of the long journeys demonstrate that international human migration is not a passing phenomenon. Equally, the historical reality of African immigrants streaming into South Africa is not an anomaly in the context of the international relations status quo and the socalled world order. However, human migration had historically reflexively reproduced itself in increasingly complex ways, rendering past experiences less insightful in the search for instruments relating to forecasting, predictability and adoption of proactive and preemptive measures. When the North African Spring started, both protagonists and critics could have accurately forecast the future history that is now unfolding with droves of Africans dying to reach European shoes. Unsurprisingly, a democratic South Africa failed to read the future from the 2008 violent abuses and killings of African immigrants. Hence, the 2015 xenophobic eruptions became another baffling embarrassment to a democratic South Africa; and, the search for causes and measures for redress remains unfinished.

Ironically, a democratic South Africa's leadership of African Renaissance through hyperboles of exceptionalism and differentness has not been neutral in the perpetration of xenophobic stereotypes, societal attitudes and perceptions against African immigrants. Concepts that were designed to be instrumental in reaffirmation of African cultures, respect of human rights, promotion of multiculturalism, inclusivity and spatial socialisation of people on either side of the borderlands, became complex virtual container-buzzwords with inconsistent 
meanings and effects enabling the unchallenged predominance of the globalist economic modernity as well as marginalisation and dispossession of lands from access of the poor sectors of the populations.

Given the centrality of governance processes and structures in the determination of access to natural resources and human habitat, increased international migration and contact came with intense cultural contestations and xenophobic stereotypes wherein concepts of "ingroups" and "out-groups" justified the "ordering and othering" of immigrants for discrimination and denial of citizenship (Jolly \& DiGiusto, 2014; Massé \& Lunstrum, 2015). Theorisation of the causes of xenophobia is wide ranging, inclusive of extremes of contact, prejudice, power, cultural-symbolism, phenomenology, threat and economic theories (Adjai \& Lazaridis, 2013; Jolly \& DiGiusto, 2014; Chinomona \& Maziriri, 2015). In Southern Africa, especially in South Africa, xenophobia came to be synonymous with violent abuses of the African immigrants (Jolly \& DiGiusto, 2014; Chinomona \& Maziriri, 2015). Thus, questions of the coexistence of ideals such as constitutional democracy, culture of human rights, multiculturalism and inclusivity with violent abuses and senseless killings of African immigrants in South Africa have to be raised. Importantly, South African political elite has championed the vision of African Renaissance, which should be founded on the ideals of pan-Africanism such as continental unity, reaffirmation of African cultures, emancipation, cooperation, sustainable economic development and democratisation (van Amerom \& Buscher, 2005 Muzeza, Schuttle \& Snyman, 2013; Barquet et al., 2014; Kark et al., 2015; Sibanda, 2015). Also, the recent hype about the Transfrontier Conservation Areas (TFCAs) or "Peace Parks" raised hopes of building peace and security in the continent, especially in Southern Africa (van Amerom \& Buscher, 2005; Martin et al., 2011; Muzeza, Schuttle \& Snyman, 2013; Barquet et al., 2014; Kark et al., 2015; Sibanda, 2015). In practice, though, the establishment of "Peace Parks" was based on the securitisation of wildlife conservation that enables Western economic philosophy of capital accumulation by dispossession of lands of the most vulnerable sections of the population whilst simultaneously characterising "others", specifically African immigrants, as dangerously armed poachers and enemies of the nation-state (van Amerom \& Buscher, 2005; Martin et al., 2011; Massé \& Lunstrum, 2015). These narratives has meant that international migration in Southern Africa is met with local society hostilities, animosities, antagonisms and violent abuses in South Africa. Also, the aphorism of "Ubuntu" and "rainbowism" abound in South Africa, African immigrants have continued to be treated with unbaiting disdain. For these reasons, it is important to understand the embeddedness of cooperation with conflict in Africa.

\section{Embeddedness of cooperation with conflict in Africa}

Conflict does coexist with cooperation in international relations (Martin et al., 2011); and, this observation is borne out in post-1990s Southern Africa where container-concepts such as African Renaissance and "Peace Parks" presented convenient buzzwords for securitisation narratives to reinforce sentiments of continentalism, reaffirmation of African cultures and pan-Africanism simultaneously with polarisation, conflict and violent rationales. South Africa's political elite has been responsible for the African unity narratives amidst fervent support and implementation of the hegemonic Western economic paradigms of "privatisation, free trade, private land ownership and the commercialisation of conservation" (van Amerom \& Buscher, 2005: 10). That is, state narratives for continental recovery, emancipation and democratisation have enabled capital accumulation through securitisation of profitable wildlife conservation as well as the dispossession of the lands of the most 
vulnerable groups of the population. In practice, the conduct of international relations by nation-states in Southern Africa during the post-apartheid era have uniformly consolidated the de jure sovereignty and fragmentary geopolitics that promote negative images of citizens on either side of the socio-economic boundaries.

Evidently, African Renaissance is an inherently politically value-laden concept and practice. Attempts to frame a depoliticised conception of African Renaissance have drawn a blank because it inescapably set power relations that re-territorialise sovereignty to reconstruct divisive geopolitical entities that describe "otherness" as unwanted enemies of the nation-state (Devine, 2014; Duffy, 2014; Lunstrum, 2014; Massé \& Lunstrum, 2015). Hence, the initiatives for regional cooperation, continental emancipation, reaffirmation of African cultures, sustainable economic development and democratisation have commonly dissipated with negligible notice. Historically, Africa's development efforts have drawn negligible pragmatic effect and expression because of the preeminence of self-interested nation-states. Hence, the continental unity expressed by leaders in terms of the scourge of xenophobic violence against African immigrants in South Africa notwithstanding, no verifiable pragmatism is on offer.

\section{Unfinished Discourses of human migration and xenophobia}

Discourses relating to human international migration and xenophobia in South Africa remain unfinished and contested. This special edition compiles articles that range from those that question the balancing of transnationalism with localisation in respect of international migration, which remains unresolved, to those that theorise the causes of xenophobia. Chigudu takes up this challenge by examining the nexus of state-sovereignty-migration. $\mathrm{He}$ locates migrants in the framework of human rights and the insistence on state sovereignty in order to reveal that migrants remain on the periphery of effective protection from the vagaries of the citizens, partly because the states' tendency to limit certain human rights to its citizenry. However, he asserts that international migration does contribute to local development. Tsheola \& Segage examine the association of the concept of governance of international relations and, by implication, human population migration, through the rigid practices of "sovereignty-state-territory triad", which foments and exacerbates societal stereotypes, attitudes and perceptions of xenophobia in Africa, in general, and South Africa, in particular. Besides highlighting the prominence of theorisation of human population migration through environmental conservation and securitisation of biodiversity that enables land dispossession of the vulnerable sections of the populations along the Western economic narratives of "Peace Parks", they demonstrate that in Southern Africa, the concept of African Renaissance has been inescapably embedded with "cooperation and conflict", offering a container-buzzword that failed to deliver reaffirmation of African cultures, continental emancipation and democratisation. To this extent, they argue that the preeminence of societal stereotypes, attitudes and perceptions of xenophobia and violent abuses of African immigrants in South Africa provides vivid illustrations of the inconsistencies and nonlinearity of concepts such as African Renaissance and "Peace Parks" for pursuit of the panAfricanism vision. From these locationing of the topical issues of human migration and xenophobia within international relations and state sovereignty, their relevance to the discipline of Public Administration is examined by Hanyane. He provides an account of the meaning and the relevance of transnationalism as both a concept and phenomenon in order to situate the topical issues of human international migration within the scope of Pubic 
Administration. Indeed, migration is a relevant subject in international relations governance, administration and management.

The cognitive search for causes of xenophobic eruptions in a democratic South Africa commences with Madue who blames the senseless acts against African immigrants on the foreign and international migration policy and doctrines omissions and exclusionism. From a Public Administration perspective and pan-Africanism philosophy, Mbecke identifies policy and strategic shortfalls and dilemmas in the New Partnership for Africa's Development (NEPAD) as the primary complicating factors that created scope for the construction of negative images and xenophobic stereotypes against African immigrants in a democratic South Africa, in the face of loud public stunts about continental recovery and respect for African cultures. This line of thought is pursued by Koenane \& Maphunye who locates the challenges of Afrophobia in a democratic South Africa on the dearth of moral and political leadership that has exposed African immigrants to untold sufferance and violent abuses in the hands of local societies. Notwithstanding the horrific experiences in a democratic South Africa, African immigration has appeared to intensify, especially in terms of the dimension commonly described as illegal. Whilst acknowledging the difficulty of understanding illegal international immigration into South Africa due to its undocumented nature, Wotela \& Letsiri examines the causes of this form of human migration which has persisted against the odds through public administration perspective on international boundaries.

On her part, Makwembere locates the causes of xenophobic violent attacks on African immigrants in the local sphere of governance of municipalities in South Africa. She argues that the local governance institutions are both irresponsible and unresponsive to the challenges of xenophobia that unfold within local societies wherein African immigrants are excluded from participation in civic affairs, thereby being exposed to stereotypes. Dassah addresses the causes of Afrophobia and/or Negrophobia associated with labeling and discrimination of African immigrants in South Africa; and, he calls for the involvement of all stakeholders in attempts to resolve the xenophobic violence. Mamabolo examines poverty and unemployment as drivers of xenophobic attacks on African immigrants in South Africa, imploring government to establish an enabling local environment for business enterprises as one of the possible remedial interventions that would dampen the violent abuses against nationals from other parts of the continent.

Xenophobia has its own impacts on local societies and the African immigrants themselves. Mothibi, Roelofse \& Tshivhase provide an analysis of the impact of xenophobic attacks on foreign nationals' business initiatives, using a case study of shops and street vending in the Central Business District of Louis Trichardt in Limpopo Province. They find that the impact go beyond material destruction of businesses to involve psychological and emotional trauma that lives with the African immigrant shop owners and street vendors, a long time after the violent xenophobic eruptions had occurred. A similar type of impact analysis is presented by Tshishonga, drawing from experiences of informal businesses in the Central Business District of Durban City in KawZulu-Natal Province. He argues that the impact of xenophobia is a double-edged sword with far-reaching implications for both South African citizens and African immigrants because informal businesses are the fulcrum of survival of the majority of residents in the City of Durban. That is, xenophobic attacks create lose-lose situation for both the local society and African immigrants. 
Academia, especially at tertiary institutions of learning, is supposed to be enlightened in terms of transnationalism and localisation of cultures for spatial socialisation. However, Sebola demonstrates that the academic expatriate project has failed to live up to its expectation of building capacity for South Africa, thereby raising questions about the conduct of the so-called star researchers recruited for the empowerment of the local society. He concedes that this project may become open-ended without a goal in sight. Apparently, the academic expatriate at tertiary institutions of learning has maintained transnational cultures, language, values and identities that impaired the potential for integration and assimilation into the local society, with the result that such African immigrants remain highly exposed for discrimination, vilification and violent abuse. However, incidents of xenophobic attacks in South Africa's tertiary education sector, if any, have never captivated national headlines.

Perhaps, the South African academia could be aloof from the challenges afflicting the local societies because these topical issues of human migration and xenophobia in Africa have not featured much in research and curricula. In the final analysis, this special edition should ask if new South Africanism has inaugurated a fascist culture within local societies. There is no verifiable powerful political system of rules, legislation, regulations and state control nor sentiments of extremist nationalistic pride and racist/ethnicist reverence to warrant characterisation of xenophobic eruptions in South Africa as "new racism". Using a case of tertiary education sector, Sithole examines the question whether new South Africanism is basically hateful of "otherness" by exploring attitudes of the educated elite towards guys, lesbians, bisexual and transgender students. Whereas his finding confirm widespread discrimination and abuse of these groups in the tertiary education sector, it remains untenable to conclusively characterise the local society as generally hateful of "otherness'. But pertinent questions arise with these inhuman treatment of African immigrants and other groups in South Africa; and, one of them is whether or not the local society is fascist. Indeed, the sensitive topical issues of African immigration, spatial socialisation, transnationalisation, localisation, cultural genocide and xenophobia in Southern Africa continue to be unresolved discourses and unfinished narratives.

However, Muswede offers an examination of the prospects of power of community radio being explored to popularise appropriate narratives to undermine the negative images, stereotypes and perceptions that foments xenophobia against African immigrants in South Africa. He recommends for a participatory community radio programming of interventions to promote peace- and trust-building narratives within the local societies as means of influencing the communal scripts against xenophobia. This special edition compilation is paradoxically concluded with an article co-authored by Tsheola, Ramoroka \& Muzondi, who theorise collective threat among in-group communities against out-group African immigrants over the untenable alibi of job and women stealing as well as acceptance of below minimum wages as functions of irrational jealousy. They frame this argument through a rigorous examination of theorisation of xenophobia as "new racism", models of governance of xenophobic societal attitudes for public hostilities, animosities and violent abuse, in order to question the role of constructions of new South Africanism, African Renaissance, exclusionary citizenship, exceptionalism, differentness and exclusionism in agitating for intolerance and xenophobic propensities within local societies. In the final analysis, tis compilation points to unfinished stories and discourses about new South Africanism and its association with the unpredictable xenophobic stereotypes, attitudes and perceptions. 


\section{Conclusion}

The search for conceptual instruments for forecasting local societal xenophobic stereotypes, attitudes and perceptions against African immigrants has to continue. Equally, the latter's propensity to uphold distinct transnational cultures, values and languages within local societies has to be addressed in order to repair the distinctness with which such African immigrants are easily identifiable and targeted for violent abuses. Further, it is recommendable that the container-buzzwords such as Ubuntu, rainbowism, African Renaissance, new South Africanism, "Peace Parks", constitutional inclusivity, discriminatory citizenship and re-territorialised post-colonial sovereignty, among others, should be rigorously examined for their role in disabling spatial socialization of Africans across "nationstate" socio-political boundaries and geopolitical entities, whilst simultaneously enabling dispossession of the poor rural communities, Western economic philosophy-based capital accumulation, undermining the revaluation of African cultures, continental emancipation and democratization. Perhaps, these lines of investigation could unveil the true causes underlying local societies' xenophobic propensities and violent abuses of African immigrants in a democratic South Africa.

\section{References}

Adjai, C. \& Lazaridis, G. 2013. Migration, xenophobia and new racism in post-apartheid South Africa. International Journal of Social Science Studies, 1(1): 192-205.

Balbo, M. \& Marconi, G. 2006. International migration, diversity and urban governance in cities of the South. Habitat International, 30: 706-715.

Barquet, K., Lujala, P. \& Rød, J.K. 2014. Transboundary conservation and militarised interstate disputes. Political Geography, 42: 1-11.

Brown, R.P.C. \& Connell, J., 2004. The migration of doctors and nurses from South Pacific Island Nations. Social Science \& Medicine, 58: 2193-2210.

Chinomona, E. \& Maziriri, E.T. 2015. Examining the phenomenon of xenophobia as experienced by African immigrant entrepreneurs in Johannesburg, South Africa: Intensifying the spirit of "Ubuntu." International Journal of Research in Business Studies and Management, 2(6): 20-31.

Dallimer, M. \& Strange, N. 2015. Why socio-political borders and boundaries matter in conservation. Trends in Ecology \& Evolution, 30(3): 132-139.

Devine, J. 2014. Counterinsurgency ecotourism in Guatemala's Maya biosphere reserve. Environmental Planning D: Society \& Space, 32: 984-1001.

Duffy, R. 2014. Waging a war to save biodiversity: The rise of militarised conservation. International Affairs, 90(4): 819-834.

Iossifova, D. 2013. Searching for common ground: Urban borderlands in a world of borders and boundaries. Cities, 34: 1-5.

Kark, S., Tulloch, A., Gordon, A., Mazor, T., Bunnefeld, N. \& Levin, N. 2015. Crossboundary collaboration: Key to the conservation puzzle. Current Opinion in Environmental Sustainability, 12: 12-24.

Lunstrum, E. 2013. Articulated sovereignty: Extending Mozambican state power through the Great Limpopo Transfrontier Park. Political Geography, 36: 1-11. 
Lunstrum, E. 2014. Green militarisation: Anti-poaching efforts and the spatial contours of Kruger National Park. Annals of the Association of American Geographers, 104(4): 816832.

Martin, A., Rutagarama, E., Cascao, A., Gray, M. \& Chhotray, V. 2011. Understanding the co-existence of conflict and cooperation: Transboundary ecosystem management in the Virunga Massif. Journal of Peace Research, 48(5): 621-635.

Masse, F. \& Lunstrum, E. 2015. Accumulation by securitisation: Commercial poaching, neoliberal conservation, and the creation of new wildlife frontiers. Geoforum, http://dx.doi.org/10.1016/j.geoforum.2015.03.005

Moilanen, A. \& Arponen, A. 2011. Administrative regions in conservation: Balancing local priorities with regional to global preferences in spatial planning. Biological Conservation, 144: 1719-1725.

Moses, J.W. \& Letnes, B. 2004. The economic costs to international labour restrictions: revisiting the empirical discussion. World Development, 32(10): 1609-1626.

Muzeza, D., Schutte, D.W. \& Snyman, R. 2013. Great Limpopo Transfrontier Conservation governance in Southern Africa: Understanding contestations and conflict between local resource access and biodiversity conservation. International Journal of Innovative Research E Development, 2(6): 187-227.

Pereira, L.M. \& Ruysenaar, S. 2012. Moving from traditional government to new adaptive governance: The changing face of food security responses in South Africa. Food Security, 4: 41-58.

Sibanda, M. 2015. Rhythms of power and institutional reengineering in conservation. Journal of Sustainable Development in Africa, 17(2): 77-96.

Thondhlana, G., Shackleton, S. \& Blignaut, J. 2015. Local institutions, actors, and natural resource governance in Kgalagadi Transfrontier Park and surrounds, South Africa. Land Use Policy, 47: 121-129.

van Amerom, M. \& Buscher, B. 2005. Peace parks in Southern Africa: Bringers of an African Renaissance? Journal of Modern African Studies, 43(2): 1-24. 